Vaal River area, a second by Dr. C. van Riet Lowe on the older gravels of the Vaal, their industrial contents and the relationships with successive pluvial and interpluvial periods, while a third, by Dr. A. L. du Toit, is a note on the older gravels of the Vaal between Barkley West and Windsorton. Much important work is being done just now in South Africa not only in correlating the various cultural stone-age levels with the successive climate changes, but also in the intensive typological and technological study of industries made mainly from non-flint material. The raw material occurs in large blocks; and the frequent occurrence in Stellenbosch industries of the so-called Clacton platform would seem to show that this method of breaking up large blocks of raw material is in no sense typical of any particular culture, but was used freely when fashioning a nucleus from large lumps of refractory material. The diagram correlating the various phases of the Stellenbosch culture and the middle and later stone ages with the climate changes will especially interest students and give rise to some earnest thought. Dr. du Toit's note is purely geological and is concerned with the actual formation of the various gravels. This series of pamphlets issued by the Survey is always interesting; but to those concerned with correlations and the earlier industries this number is of vety considerable importance.

\section{Mortality of Adult and Young Mallards}

A Recent ex Mination by E. O. Höhn of the recovery tis of mallards (Anas p. platyrhynca) ringed pnd the British Birds marking scheme shows an in tresting difference in length of survival of biy is 1 nged as adults as compared with those rinted as young (British Birds, 41, No. 8; August 1948). Ringing recoveries of 305 adult mallards showed that $65 \cdot 3$ per cent died during the first year after ringing, 23.9 per cent during the second year, 6.6 per cent during the third year and 4.2 per cent during subsequent years. The average length of further survival from the date of ringing was one year and two months. Of 828 mallards ringed as young, 89 per cent died during the first year after ringing, 9.6 per cent during the second year, 0.6 per cent during the third year and 0.8 per cent during succeeding years. The average period of survival was 4.5 months after ringing. The mortality recorded by jühn is almost entirely due to shooting.

\section{Photometric Elefints of a Binary Star}

A Paper by L. Baglow (Mon. Not. Roy. Ast. Soc., 108 ( 4 ; 1948) on "The Photometric Elements of RS Sagittarii" is based on R. O. Redmat's observations of the star, a description of wich has already been published (Mon. Not. Roy. Afloc., 105, 212; 1945). Redman's measurements weje made photographically by the Fabry method and refer to an effective wave-length of $4400 \mathrm{~A}$. ; these are shown in two figures together with a theoretical curve for both minima, computed by Baglow. Tables were calculated for various degrees of darkening, utilizing those given by Russell and Shapley, and elements were finally computed for an assumed coefficient of limb-darkening $u$ equal to $0 \cdot 4$. The spectral type of the brighter star is given as B5, but that of the fainter one has not yet been observed. For the purpose of calculating the correction for reflexion it was assumed to be of type $A 0$; but until its spectrum has been observed the absolute dimen. sions of the system cannot be accurately determined, nor can the observed ellipticity of the components be compared with theoretical expectations. Table 3 of the paper shows the dimensions of the system for three different assumptions of the mass ratio, $1 \cdot 0$, 0.5 and 0.2 , leading to the radii of the relative orbits as $4 \cdot 7,7 \cdot 0$ and 14 million $\mathrm{km}$., respectively. It is believed that $R S$ Sagittarii is a normal eclipsing binary with a circular orbit, the secondary star being considerably less massive than the primary but comparable in size with it. Suitable spectroscopic observations of the system could greatly reduce the large uncertainties in the photometric results.

\section{Board of Greenkeeping Research: St. Ives Station, Bingley}

AT the annual meeting of the Board of Green. keeping Researeh in Leeds on February 11, 1949, the director of the St. Ives Research Station, Mr. R. B. Dawson, presented his report on the Station's activities furing 1948. In spite of a shortage of staff, the work has increased, and research has continued on mghy of the old experiments put down early in the station's history. New work has been done on sq stabilization with bitumen, seeds mixtures, growth substances for the control of weeds, and worm control. The advisory work carried out during the year has been very heavy. Visits to subscribing clubs, the Station's postal advisory service and the number of samples from clubs which were handled by the laboratory, all showed substantial increases in the 1948 figures as compared with 1947. In addition to the $p \mathrm{H}$, lime requirement and the phos. phate status, the reports of the laboratory analyses of club samples now include the potash status. Golf clubs in Great Britain have continued their support, and there has been a marked increase in the support from municipalities and clubs. Educational work has been kept up in that many lectures have been given to outside bodies, and six courses of instruction for groundsmen have been arranged at the Station.

\section{British Commonwealth Specialist Agricultura! Con- ference in Australia}

IN accordance with the resolution of the 1946 British Commonwealth Scientific Official Conference, a Specialist Conference in Agriculture will be held in Australia guring August 22-September 15, 1949. The theme of the Conference is "Plant and Animal Nutrition in Relation to Soil and Climatic Factors", with emphasis on 'nutrition' interpreted broadly as whl-being, and it is intended that the meeting shall consist of informal discussions between workers actively engaged in this field. The Conference, which is being organised by the Australian Council for Scientific and Industrial Research, will commence in Adelaide, South Australia, for the period August 22-31, when sessions $A, B, C$ and $D$ will be held. This will be followed by an official twelve-day tour through southern South Australia, Victoria and southern New South Wales, and the final sessions, $E$ and $F$, and winding-up will be at Canberra during September 13-15. Official invitations have been made to each member country of the British Commonwealth, and some fifty delegates will be noninated. In addition, some invited contributors from other countries, from the United States, for example, will be attending. Travelling expenses and subsistence of the delegates will be borne by their respective countries; but the Australian Government is financing the twelve-day tour. The papers for the Conference will fall into three main groups : $(a)$ officially invited papers ; (b) 